\title{
The dentist-scientist career pathway in Africa: opportunities and obstacles
}

\author{
Henry Ademola Adeola ${ }^{1,2}$, Anthonio Adefuye ${ }^{3}$, Olujide Soyele ${ }^{4}$ and Azeez Butali ${ }^{5}$ \\ ${ }^{1}$ Department of of Oral and Maxillofacial Pathology, Faculty of Dentistry, University of the Western Cape, ${ }^{2}$ Division \\ of Dermatology, Faculty of Health Sciences, University of Cape Town, Cape Town, ${ }^{3}$ Division of Health Sciences \\ Education, Office of the Dean, Faculty of Health Sciences, University of the Free State, Bloemfontein, Republic \\ of South Africa, ${ }^{4}$ Department of Oral Maxillo-Facial Surgery and Oral Pathology, Obafemi Awolowo University, \\ Ile-Ife, Nigeria, and ${ }^{5}$ Department of Oral Pathology, Radiology and Medicine, University of lowa, lowa City, \\ IA, USA
}

The future of evidence-based dentistry in developing Africa heavily depends on a sustainable establishment of a vibrant dentist-scientist workforce. A dentist scientist is saddled with the responsibility of carrying out robust cutting edge research projects that are inspired by clinical experience. Currently, there are no pipelines in place to systematically train such dentists, neither are there programs in place to allow trained African dentists choose such a career pathway. A dentist-scientist is a person who studied oral, dental, maxillofacial (or craniofacial) diseases, prevention, and population sciences (obtaining a medical degrees such as bachelor of dental surgery [BDS] or BChD) alone; or in combination with other advanced degrees such as doctor of dental surgery (DDS)/doctor of philosophy $(\mathrm{PhD})$ or $\mathrm{BDS} / \mathrm{PhD}$. This situation has resulted in overdependence of African clinical practice on research findings from technologically advanced Western countries and a decline in clinical research capacity building. The career path of a dentist-scientist should involve research along the spectrum of basic biomedical sciences, translational, clinical and public health sciences. There are several factors responsible for the ultra-low count of dentist-scientist in the heterogeneous African communities such as: poor biomedical research infrastructure; lack of funding; absence of structured dentist scientist career pathways; lack of personnel, inter alia. Hence, this review hopes to discuss the opportunities of setting up a dentist-scientist training pathway in Africa (as obtains in most developed world settings), identify opportunities and prospects of developing an African dentist-scientist workforce, and finally discuss the challenges involved.

Key Words: Dental education, Dental research, Africa, Career choice, Dentistry

\section{Introduction}

In the era of precision and personalized medicine, it is important for the African continent to equip itself with the requisite workforce that can handle and make sense of knowledge acquired from gene sequencing and genomics, proteomics, molecular imaging, bioinformatics and big data mining. This could improve the development of individualized therapies for diseases in Africans. Understandably, the biomedical research community in Africa has faced diverse internal and external bottlenecks over the years [1]. However, it is apparent that Africa is overdue for developing innovative research
Received: May 17, 2018 • Revised: July 12, 2018 • Accepted: July 16, 2018 Corresponding Author: Henry Ademola Adeola (https://orcid.org/0000-0003-2896-0583) Faculty of Health Sciences, University of Cape Town, Anzio Road, Observatory, Cape Town, Republic of South Africa

Tel: +27.21.650.3729 Fax: +27.21.650.3729 email: henry.adeola@uct.ac.za
Korean J Med Educ 2018 Sep; 30(3): 189-198.

https://doi.org/10.3946/kjme.2018.93 eISSN: 2005-7288

(C) The Korean Society of Medical Education. All rights reserved. This is an open-access article distributed under the terms of the Creative Commons Attribution Non-Commercial License (http:// creativecommons.org/licenses/by-nc/3.0/), which permits unrestricted non-commercial use, distribution, and reproduction in any medium, provided the original work is properly cited. 
programs that systematically addresses its unique clinical conditions and disease burden. Even in the developed world, it has been reported, that there are disparities in biomedical research funding for ethnic minorities via government funding mechanism, and that increasing minority representation could promote better science [2] Although, a huge burden of various diseases are found in Africa, it is unfortunate that there is still a very low amount of cutting edge health research originating from this region [3-5]. The lack of structured career paths within biomedical research institutions and medical schools is a major problem, albeit the problem facing biomedical research in Africa is multidimensional [6]. Not least, biomedical sciences curricula in most African medical schools do not inspire student to consider medical research as a career path; neither does it provide teaching in latest advances in the medical field [6].

The dental practitioner, academic and research communities in Africa need to contribute towards the establishment of a dentist-scientist workforce in Africa in order to address burden of dental diseases in Africa. In the era of precision medicine, novel discoveries in biomedical sciences is redefining the conduct of medical research and human health improvement [7]. However, the integrity of medical research in Africa depends heavily on the quality of data and knowledge of the health personnel involved in the data collection [8]. Despite these burgeoning body of relevant scientific knowledge emanating from biomedical research, only a few find their way into clinical application [9-11]; clinical problems are hardly translated into research projects [12]. Dentist-scientists are catalysts of translational research because they are able to bridge the gap between bedside and the laboratory while engaging research and clinical practice $[13,14]$. Having such a workforce in Africa would enhance the translation of basic research findings into clinical application, as well as developing clinically relevant research questions which are translated from the bedside into basic research [15-17]. Translational research is highly important to international health policies, development initiatives, and research funding [18]; and African governments need to create an enabling environment for translational research among its dental health care providers. A decline in medical/clinical research output and capacity has been found in Africa as a result of low counts of clinician-scientists [19]. Although the support of the pure scientist is needed to tackle dental research problems that emanate from clinical observation, dental practitioners should play a more important role in addressing these problems [20]. Over the years, medical science has experienced a shift from clinician-scientists focusing on a single problem to multidisciplinary team science focused at solving a complex problems of significance to the society at large [21].

\section{The dentist-scientist workforce: status quo in Africa versus global scenario}

With the ever changing clinical standard practice, biomedical research is deemed a powerful tool for addressing challenging in healthcare delivery [22]. Currently, innovative advances in biomedical sciences have paved a way for rapid diagnosis and treatment monitoring of diseases [23]. The increase in African health research publications mostly contributed by South Africa, Nigeria, and Kenya, does not necessarily equate an acceptable level of health research in the continent [24]. Overdependence of medical practice on scientific evidence from the developed world, which is obtained in most Africa countries, has not permitted the much desired advancement in the management of many diseases in the African setting [25]. Generally, expertise is deficient in 
evidence-based research, and research suggested this as a major attributable factor responsible for low research capacity in Africa. There are very few physician scientists in Africa and even rarer are dentist-scientists.

On the other hand, many developed economies have perfected ways to systematically incorporate science and research into dental practice. For example, the National Institute of Dental Research (NIDR) was established in America in 1948, and was highly instrumental in weaving science and technology research into the American dental schools, as well as applying science to inform the routine practice of oral healthcare [21]. After 50 years of remarkable expansion of the research and training portfolio of the NIDR, the name was changed to the National Institute of Dental and Craniofacial Research (NIDCR) in 1998 [21]. However, between 1999 and 2012, the number of grant applications awarded to dentistscientist is on the decline and there are also low numbers of new dentist-scientist investigators that apply for the National Institute of Health (NIH) early career programs [26]. As an emerging economy, there is a vibrant increase in the dental science research of Brazil and there seems to be a relative increase in dental research productivity (adjudged by h-index) of Brazil as compared to the United States [27].

A recently completed NIH study showed that growth of new doctor of philosophy (PhD) scientists who hold an NIH Research Project Grant surpassed that of physician-scientists [28]. Globally there is a continual decline in the physician-scientist workforce that hold the NIH Research Project Grant, but it follows an aging trend of established physician-scientists getting more NIH Research Project grants than early career physician-scientists [28]. This bottleneck that start-up dentist-scientists experience in technologically advanced societies would affect young and aspiring dentistscientists even more in Africa. In the sub-Saharan
African region, there is lack of clinically trained dentalresearch scientists and minimal or no support for those existing [19]. To tackle the present precarious healthcare burdens appropriately, Africa need well-trained dentistscientists workforce to train future dental researcher and to lead research endeavours across the continent, and further afield.

Africa is a continent plagued by continuous and massive emigration of clinicians to technologically advanced and high income countries [29]. The current capacity of the dentist-scientists workforce in Africa is unknown as compared to an approximate 9,000 physician-scientists declared by the United States in 2012 with NIH research project grants [28]. Although there is a persistent decline in the physician-scientists workforce in developed countries $[14,30,31]$, the paucity of dentally trained research scientists in Africa could present with retarded progress of evidence-based dentistry in Africa.

\section{Innovative approaches to increasing the dentist-scientist workforce in Africa}

\section{Inclusion of research modules in under- graduate and post-graduate dental curri- culum}

Involving medical and dental trainees in translational clinical research all through medical school and during residency training has been proposed as a way of increasing the physician-scientist workforce [31]. In fact, in 2009, the Association of American Medical Colleges has recommended that clinical research training be accelerated and restructured in undergraduate and graduate medical education curricula in order to increase the population of physician-scientist workforce [32]. Thus various training programmes such as the doctor of 
medicine- $\mathrm{PhD}$ and doctor of dental surgery (DDS)-PhD pathway have been established in medical colleges in the United States to ensure continued production of physician-scientists [33]. In Africa, translational clinical research is yet to be incorporated into undergraduate curriculum of many medical schools [34]. Hence, there is an urgent need to re-evaluate and improve research capacity and training among dental trainees in Africa [35].

\section{Government funded training programmes are needed}

There is a dearth of dental scientist around the world and the situation is worse in developing countries. While most developed countries have taken a systematic approach to training and nurturing dental scientists, countries in Africa have yet to come up with any plans at all. In this section, we will review the dental scientist training pathways in the United States and propose a similar pathway in Africa.

The National Institute for Dental and Craniofacial Research is the primary institute at the NIH responsible for the training of dental scientists. These trainings are both intramural and extramural. The focus of this review will be on the extramural training where most of the dental scientists are produced.

DDS/PhD track: This program allows dental students to pursue a combined degree with emphasis on clinical and basic science research training. These students are enrolled in the DDS program and take courses in the first through fourth year of dental school. They are conferred with a DDS degree in the fourth year before starting their $\mathrm{PhD}$ program from the 5 th to the 7 th year. To ensure students are exposed to research experiences, most $\mathrm{DDS} / \mathrm{PhD}$ students participate in the Student Undergraduate Research Training. After obtaining their DDS degrees, they are also given opportunities to practice for 1-2 days each week to ensure they maintain their clinical skills. Most of these individuals are also encouraged to pursue an advanced training in any of the dental specialty to increase their chances of a successful clinical and research faculty career. This program is usually funded through an institutional training grant from the NIH (T-90) or through direct individual fellowships (T-32) offered by the NIH to institutions based on merits and after peer-review. Of the 65 dental schools in the United States, only 18 of them offer $\mathrm{DDS} / \mathrm{PhD}$ programs and currently enrol one to two students per year [36]. The low number of trainees is a major reason for the dearth in dental scientists. Nonetheless, it is obvious that there is a deliberate attempt to increase the dental scientist pool.

Additional strategies to increase this pool have been designed and implemented and these include: the dental scientist path to independence award (k99/R00) which is a 2 years mentored fellowship program for dentist with $\mathrm{PhD}$ and support for 3 years to become independent. There are also the $\mathrm{K}$-awards (K01, K08, and K23) for young and middle level clinical faculty to become mentored in research for 2-3 years and support for 3 years as independent research faculty. Overall, these training mechanisms have enriched the dental scientist pool in the United States.

Is this possible in Africa? The answer is "yes." Using the current dental training in Nigeria as an example, students can graduate after 6 years of dental school and commence their $\mathrm{PhD}$ training program immediately for 3 years. During the $\mathrm{PhD}$ program, they should be offered stipends commensurate with what first year residents earn. They should be allowed to practice for 2 days a week in a role similar to that of a house officer. This will help maintain their clinical skills. Upon completion of the $\mathrm{PhD}$, they should be offered adjunct faculty positions as well as a place in postgraduate residency in any specialty of their choice in order for them to become 
Fig. 1. Proposed Model for Training Competitive Densist-Scientists in Africa

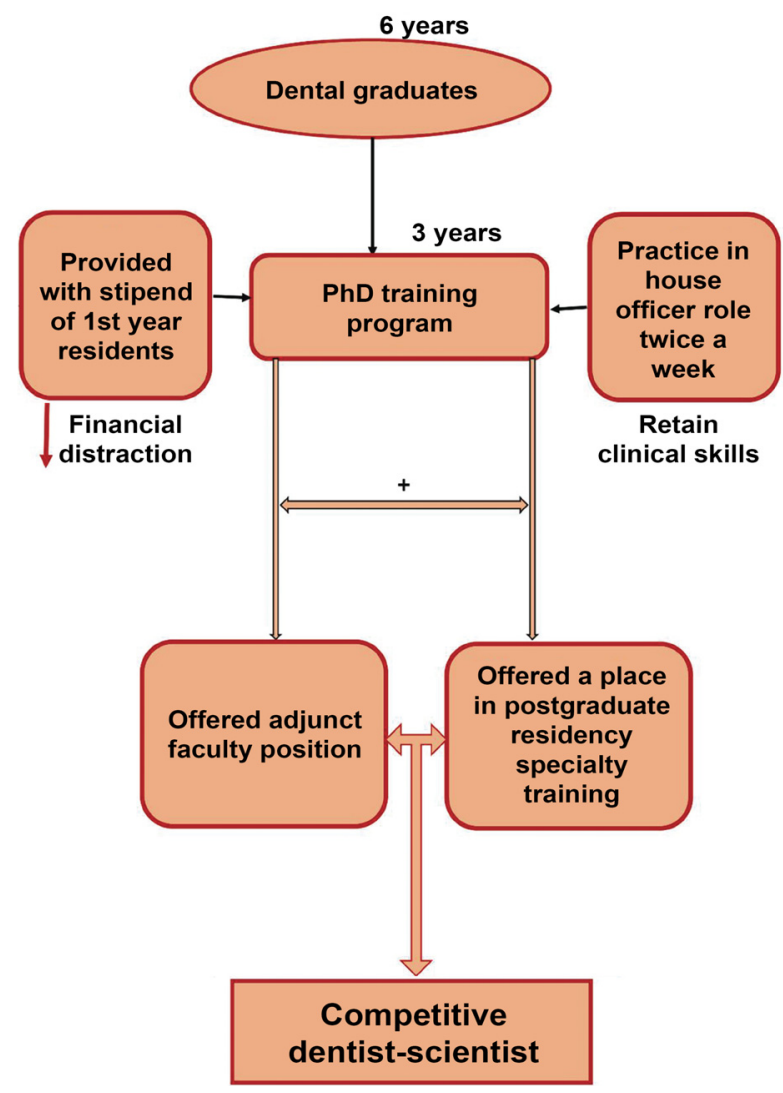

competitive (Fig. 1). This program must be funded by the federal government and funds should be set aside in an endowment to ensure continuity and uninterrupted training.

How is this different from status quo? The proposed $\mathrm{DDS} / \mathrm{PhD}$ program will be a game changer with multitudes of benefits to the dental scientist pool in Africa. Currently, individuals go through dental school for 6 years with no formal training in research, work as house officers for 1 year and serve the country for another year. They spend 2-3 years in private practice before starting postgraduate residency training. After 6 years of residency, they are employed as faculty with little or no research experience beside the minimal requirement before their fellowship is conferred. The majority of the faculty in dental schools in Nigeria went through this route and the result is evident on the level of dental research in the country. A few changed their training route and took additional postgraduate degrees like $\mathrm{PhDs}$ and master of public health and these individuals have distinguished themselves as successful scholars. It takes a minimum of 14 years to become a faculty under the current arrangement and a fixed 15 years to become a faculty through the dental scientist pathway. As it is in the United States, Nigeria and other African countries can start small by enrolling one or two trainees in three to five dental school each year into a dental scientist training program. In 10 years, there will be a critical mass of dental scientist and downstream effect on clinical basic, and translational research in dentistry will be unprecedented.

\section{Improving the physician-scientist work- force in Africa: South African case example}

\section{National Health Scholars Programme}

The South African Ministry of Health made a pronouncement to train $1,000 \mathrm{PhDs}$ in health sciences through the National Health Scholars Programme over the next 10 years as a result of a steady decline in clinical research capacity in South Africa [37]. This is aimed at increasing the number of physician-scientists workforce in the country. The $\mathrm{PhD}$ Scholarships are awarded to health professionals for full-time doctoral research to be conducted in health sciences.

\section{Clinician Researcher Programme: South African Medical Research Council}

Another funding provided for dentist-scientists is the South African Medical Research Council-Clinician Researcher Programme, which is a full time $\mathrm{PhD}$ scholar- 
ship awarded to medical or dental graduates to conduct clinical or biomedical research. Beneficiaries of the scholarship are expected to spend at least $90 \%$ of their time conducting research and 10\% on teaching and clinical activities.

\section{Academic institution initiatives for physician- scientist training in South Africa}

A few universities in South Africa have developed initiatives that would empower clinicians to pursue a physician-scientist career pathway. For example, the University of Witwatersrand-Carnegie $\mathrm{PhD}$ Programme provides 2-year funding for clinicians with MMed (master of medicine) or $\mathrm{MChD}$ (Medicinae ac Chirurgiae Doctoranda) to pursue a $\mathrm{PhD}$ [19]. Even though this program has enrolled up to 16 fellows, its sustainability is being threatened by the availability of local funders. Also, at the University of Cape Town, intercalated bachelor of science (med) honours/bachelor of medicine and bachelor of surgery (MBChB) and integrated $\mathrm{MBChB} / \mathrm{PhD}$ tracks are available to undergraduate medical students at the end of the second year of the $\mathrm{MBChB}$ programme. This training pathway consists of a basic medical sciences research and coursework component; as well as a clinical training component, at the end of which an $\mathrm{MBChB} / \mathrm{PhD}$ degree would be awarded [38]. Even though these programmes are available, for $\mathrm{MBChB} / \mathrm{PhD}$ pathways, we are not aware of any such pathways for dentist-scientists.

\section{Obstacles to training and retention of dentist-scientist in Africa}

\section{Infrastructure}

Most countries in Africa have succeeded in training home bred physicians, who are equipped with baseline training in biomedical sciences. However, the high cost of biomedical infrastructure and laboratory set-up, has prevented many research and science enthusiasts from following a physician-scientist pathway [6].

\section{Remuneration}

Moreover, physicians who decided to follow the biomedical research pathway are poorly remunerated in comparison to their clinician counterpart [39]. This disparity in remuneration and poor training infrastructure makes the choice of becoming a physician- or dentist-scientist less attractive in the African setting. Most African doctors who are determined to pursue this career path often tend to go in search of such opportunities overseas.

\section{Research funding}

A vital benefit of training physician- or dentistscientists is their commitment towards preventive and improved therapeutic management of diseases [13]. However, funding is major factor to consider in sustaining a physician-scientist career [13,39]. Although Africa bears up to $90 \%$ of the global disease burden, it only has access to about $10 \%$ of global health research funding [40]. Governmental research funding for dentists and doctors who wish to become dentist-scientists is largely unavailable. In addition, most dentists are either inexperienced in research grant writing or are unwilling to pass through the rigor of securing research grants. In a dispensation when funding is being reduced due to austerity measures, the possibility of researchers losing their funding is high [39,41]. Therefore, the risk of losing such grants may be a deterrent to pursuing a dentist-scientist career in Africa. 


\section{Poor research networking}

Weak intra-Africa networking in the area of research and funding has also hindered the effective use of limited resources for the production of maximal quality science and career opportunities in Africa; as well as incentives to retain the few available scientists [40]. Good network among African medical researchers is essential and can lead to better medical and dental research output in Africa. For example, an oral pathology research consortium known as the African Oral Pathology Research Consortium has worked as a leverage for multicentre oral cancer study in Nigeria [42]. Similarly, the African Craniofacial Anomalies Network has supported the capacity building and research in genomics and genetics of craniofacial anomalies through funding from the $\mathrm{NIH}$ and Wellcome Trust [43].

\section{Lack of home-grown solution to African problems}

The high burden of various diseases in Africa [44-46], demands a home-grown solution. There is a pressing need for a vibrant and capable physician and dentistscientist workforce in Africa, to participate in clinical translational research that will accelerate personalized scientific breakthroughs in the medical field. Currently, there are no support structures established in the medical training programmes of many African countries for doctors and dentists to transition into physician-scientist career track [6]; except for a few emerging programmes being initiated by academic institutions in South Africa, as alluded to earlier $[19,38]$.

\section{High demand for basic medical services}

Owing to the high demand for basic medical services in Africa, and the need to support their respective families financially, most medical graduates in Africa are required to go into immediate employment as a service provider. Such compelling forces are most times beyond the power of the affected individuals and may contribute significantly to the unlikelihood of a medical or dental graduate pursuing a physician-scientist career pathway straight after finishing medical school. These factors militate against training clinician scientists at the postgraduate level; and medical graduates tend to opt for the more financially viable and faster enriching option. Not least, the high clinical workload mostly makes it very difficult for clinicians to secure dedicated time for research in a clinical position [13].

\section{Conclusion}

Investing in a structured dentist-scientist training programme in Africa would ensure an increase in dentistscientists workforce Africa and this would improve the systematic development of evidence based medicine for personalized medicine in the African continent. Hence, there is a pressing need for African governments to establish and support research and academic institutions that would provide better treatment for its populace. This would also enhance research capacity building for clinical research within the continent and reduce the overdependence on "first world" countries. This is possible, as we have seen as a good example in South Africa, albeit it is in its infancy. When there is a funding shortage, a physician-scientists tends to draw back to the more financially viable clinical discipline [41]. It is also recommended that medical training should involve a reasonable degree of biomedical research. The core undergraduate curriculum of most African universities need to provide science research development com- $^{-}$ petencies in order to influence the decision of African 
trained dentists to be interested in a research career after their basic dental training. African hospitals should be supported by the government, and clinicians who need dedicated time to perform basic medical research should be funded in dentistry. We also recommend that the lengthy period required for basic dental degree, specialization and a $\mathrm{PhD}$ should be shortened to incentivize clinicians who are willing to pursue a dentist-scientist pathway in Africa. This can be accomplished by the establishment programs similar to that in South Africa. Collaborative linkages are also essential across Africa to foster a support system between countries. It is highly important for African governments to act strategically in developin, a talented stream of dentist-scientists workforce. This would create a conducive environment that develops, supports and retains existing physicianscientists; and attract back those in diaspora.

\section{ORCID:}

Henry Ademola Adeola: https://orcid.org/0000-0003-2896-0583; Anthonio Adefuye: https://orcid.org/0000-0003-2380-1487; Olujide Soyele: https://orcid.org/0000-0003-3653-0815; Azeez Butali: https://orcid.org/0000-0002-1229-5964

Acknowledgements: HAA would like to thank the South African Medical Research Council for a mid-career scientist research grant.

Funding: HAA is a recipient of a mid-career scientist research fellowship from the South African Medical Research Council. This work was also supported by NIDCR K99/R00 Grant DE022378-04 and Robert Wood Johnson Foundation Grant number 72429 to AB. The funders played no role in the design or interpretation of the paper or the decision to publish.

Conflict of interest: No potential conflict of interest relevant to this article was reported.

Author contributions: HAA conceptualized, designed, prepared and critically revised the manuscript. AOA, OOS, and $\mathrm{AB}$ were involved in the design, preparation and critical intellectual revision of the paper. All authors read and approved the final manuscript submitted for publication.

\section{References}

1. Adeola HA, Soyele OO, Adefuye AO, Jimoh SA, Butali A. Omics-based molecular techniques in oral pathology centred cancer: prospect and challenges in Africa. Cancer Cell Int. 2017;17:61.

2. Oh SS, Galanter J, Thakur N, et al. Diversity in clinical and biomedical research: a promise yet to be fulfilled. PLoS Med. 2015;12(12):el001918.

3. Hotez PJ, Kamath A. Neglected tropical diseases in sub-saharan Africa: review of their prevalence, distribution, and disease burden. PLoS Negl Trop Dis. 2009; 3(8):e412.

4. Holmes MD, Dalal S, Volmink J, et al. Noncommunicable diseases in sub-Saharan Africa: the case for cohort studies. PLoS Med. 2010;7(5):el000244.

5. Chu KM, Jayaraman S, Kyamanywa P, Ntakiyiruta G. Building research capacity in Africa: equity and global health collaborations. PLoS Med. 2014;11(3):e1001612.

6. Kokwaro G, Kariuki S. Medical research in Africa: problems and some solutions. Malawi Med J. 2001;13(3): 40.

7. Zerhouni E. Medicine: the NIH roadmap. Science. 2003;302(5642):63-72.

8. Participants of an International Workshop in Kenya on the Role of Frontline Staff in Biomedical Research, July 2014, Kombe F. Enhancing quality and integrity in biomedical research in Africa: an international call for greater focus, investment and standardisation in capacity strengthening for frontline staff. BMC Med Ethics. 2015;16(1):77. 
9. Scott SD, Estabrooks CA, Allen M, Pollock C. A context of uncertainty: how context shapes nurses' research utilization behaviors. Qual Health Res. 2008;18(3): 347-357.

10. Adeola HA, Blackburn JM, Rebbeck TR, Zerbini LF. Emerging proteomics biomarkers and prostate cancer burden in Africa. Oncotarget. 2017;8(23):37991-38007.

11. Fernandez-Moure JS. Lost in translation: the gap in scientific advancements and clinical application. Front Bioeng Biotechnol. 2016;4:43.

12. Jansson SM, Benoit C, Casey L, Phillips R, Burns D. In for the long haul: knowledge translation between academic and nonprofit organizations. Qual Health Res. 2010;20(1):131-143.

13. Archer SL. The making of a physician-scientist: the process has a pattern: lessons from the lives of Nobel laureates in medicine and physiology. Eur Heart J. 2007;28(4):510-514.

14. Lander B, Hanley GE, Atkinson-Grosjean J. Clinicianscientists in Canada: barriers to career entry and progress. PLoS One. 2010;5(10):el3168.

15. Roy CC. Survival of clinician scientists. Clin Invest Med. $1997 ; 20(4): 283-288$.

16. Estabrooks CA, Norton P, Birdsell JM, Newton MS, Adewale AJ, Thornley R. Knowledge translation and research careers: Mode I and Mode II activity among health researchers. Res Policy. 2008;37(6-7):1066-1078.

17. Kennedy PG. My life as a clinician-scientist: trying to bridge the perceived gap between medicine and science. DNA Cell Biol. 2015;34(6):383-390.

18. Fudge N, Sadler E, Fisher HR, Maher J, Wolfe CD, McKevitt C. Optimising translational research opportunities: a systematic review and narrative synthesis of basic and clinician scientists' perspectives of factors which enable or hinder translational research. PLoS One. 2016;11(8):e0160475.

19. Kramer B, Veriava Y, Pettifor JM. Rising to the challenge: training the next generation of clinician scientists for South Africa. Afr J Health Prof Educ. 2015;7(2):153-154.

20. Darling AI. Dentistry: a science? J R Soc Med. 1978; $71(5): 323$

21. Slavkin HC. Evolution of the scientific basis for dentistry and its impact on dental education: past, present, and future. J Dent Educ. 2012;76(1):28-35.

22. Califf RM, Robb MA, Bindman AB, et al. Transforming evidence generation to support health and health care decisions. N Engl J Med. 2016;375(24):2395-2400.

23. McKillop AM, Flatt PR. Emerging applications of metabolomic and genomic profiling in diabetic clinical medicine. Diabetes Care. 201 1;34(12):2624-2630.

24. Uthman OA, Wiysonge CS, Ota MO, et al. Increasing the value of health research in the WHO African Region beyond 2015: reflecting on the past, celebrating the present and building the future: a bibliometric analysis. BMJ Open. 2015;5(3):e006340.

25. Omolase CO, Egberongbe AA, Komolafe OO, Olasinde AA, Omolase BO, Adeosun OA. Practice of bio-medical research amongst doctors in Owo. S Afr Fam Pract 2015;57(2):112-115.

26. D'Souza RN, Colombo JS, Embree MC, Myers JM, DeRouen TA. Our essential and endangered dentistscientist workforce. JDR Clin Transl Res. 2017;2(1): $10-22$.

27. Normando D. The Brazilian dental science. Dental Press J Orthod. 2014;19(2):14.

28. Deligiannidis KM. The physician-scientist workforce in the United States. Acta Psychiatr Scand. 2015;132(4): $317-318$

29. Tankwanchi AB, Ozden C, Vermund SH. Physician emigration from sub-Saharan Africa to the United States: analysis of the 2011 AMA physician masterfile. PLoS Med. 2013;10(9):el001513.

30. Kosik RO, Tran DT, Fan AP, et al. Physician scientist 
training in the United States: a survey of the current literature. Eval Health Prof. 2016;39(1):3-20.

31. DeLuca GC, Ovseiko PV, Buchan AM. Personalized medical education: reappraising clinician-scientist training. Sci Transl Med. 2016;8(321):32lfs2.

32. Schafer AI. The vanishing physician-scientist? Transl Res. 2010;155(1):1-2.

33. Koniaris LG, Cheung MC, Garrison G, Awad WM Jr, Zimmers TA. Perspective: PhD scientists completing medical school in two years: looking at the Miami $\mathrm{PhD}$-to-MD program alumni twenty years later. Acad Med. 2010;85(4):687-691.

34. Ogeng'o JA, Mwachaka PM, Bundi PK. Factors influencing research activity among medical students at University of Nairobi. Ann Afr Surg. 2010;6(1):1-4. https://doi.org/10.4314/aas.v6il.63232.

35. Ibrahim A, Asuku ME. Stimulating medical students interest in research: a neglected craft in Africa. Pan Afr Med J. 2012;13:12.

36. Rogér JM. A survey of dual-degree training opportunities at US dental schools. J Dent Educ. 2006;70(9):909-917.

37. Mayosi BM, Lawn JE, van Niekerk A, et al. Health in South Africa: changes and challenges since 2009. Lancet. 2012;380(9858):2029-2043.

38. Katz AA, Futter M, Mayosi BM. The intercalated BSc (Med) Honours/ $\mathrm{MB} \mathrm{ChB}$ and integrated $\mathrm{MB} \mathrm{ChB} / \mathrm{PhD}$ tracks at the University of Cape Town: models for a national medical student research training programme. S Afr Med J. 2014;104(2):111-113.
39. Pickering CR, Bast RC Jr, Keyomarsi K. How will we recruit, train, and retain physicians and scientists to conduct translational cancer research? Cancer. 2015; 121(6):806-816.

40. Kitua AY, Corrah T, Herbst K, et al. Strengthening capacity, collaboration and quality of clinical research in Africa: EDCTP Networks of Excellence. Tanzan J Health Res. 2009;11(1):51-54.

41. Gordon R. The vanishing physician scientist: a critical review and analysis. Account Res. 2012;19(2):89-113.

42. Omitola OG, Soyele OO, Sigbeku O, et al. A multi-centre evaluation of oral cancer in Southern and Western Nigeria: an African oral pathology research consortium initiative. Pan Afr Med J. 2017;28:64.

43. Butali A, Mossey P, Tiffin N, et al. Multidisciplinary approach to genomics research in Africa: the AfriCRAN model. Pan Afr Med J. 2015;21:229.

44. Owolabi MO, Akarolo-Anthony S, Akinyemi R, et al. The burden of stroke in Africa: a glance at the present and a glimpse into the future. Cardiovasc J Afr. 2015; 26(2 Suppl 1):S27-S38.

45. Brinton LA, Figueroa JD, Awuah B, et al. Breast cancer in Sub-Saharan Africa: opportunities for prevention. Breast Cancer Res Treat. 2014;144(3):467-478.

46. Adeloye D, David RA, Aderemi AV, et al. An estimate of the incidence of prostate cancer in Africa: a systematic review and meta-analysis. PLoS One. 2016;11(4): e0153496. 